Wang Dianlong, Diao Guangyun and Liang Zhimin*

\title{
Comparison of Al-Zn-Mg Alloy P-MIG Welded Joints Filled with Different Wires
}

https://doi.org/10.1515/htmp-2017-0146

Received October 16, 2017; accepted May 22, 2018

\begin{abstract}
Three kinds of welding filler wires, named ER5356, ER5087 and ER4043, were used to joint $12 \mathrm{~mm}$ thick Al-Zn-Mg alloy plate by the pulsed MIG(P-MIG) welding. The microstructure and mechanical properties of the joints were analyzed and compared. The results showed that the average tensile strengths of the joints filled with ER5356, ER5087 and ER4043 were $294 \mathrm{MPa}$, $313 \mathrm{MPa}$ and $237 \mathrm{MPa}$, respectively, and the average elongations were $7.9 \%, 7.6 \%$ and $1.6 \%$, respectively. All the joints's fracture locations were near the fusion boundary. The microhardness test showed that the locations of the lowest hardness were all in the center of cross section. The results revealed that the weld filler by ER5087 was consist of more columnar crystals of larger grain size, while the weld filled by ER5356 was consist of more equiaxed grains of smaller grain size. The microstructure of the weld by ER4043 was typical eutectic dendrites structure.
\end{abstract}

Keywords: welding filler wire, aluminum alloy, microstructure, mechanical properties, P-MIG welding

\section{Introduction}

$\mathrm{Al}-\mathrm{Zn}-\mathrm{Mg}$ aluminum alloy is an ideal high-strength structural material due to its high specific strength, good hot workability and corrosion resistance. It is widely used in high-speed train body structure and aeronautical industry [1-4]. The fusion welding of Al$\mathrm{Zn}-\mathrm{Mg}$ alloy has a high sensitivity to hot cracking, the choice of appropriate welding wire is the key to avoid hot cracking. Al-Si filler wire has the excellent fluidity and the best solidification cracking resistance, but the mechanical properties of the joint is poor, while the Al$\mathrm{Mg}$ filler wire has good hot cracking resistance and

*Corresponding author: Liang Zhimin, Faculty of Material Science and Technology, Hebei University of Science and Technology, Shijiazhuang 050018, P.R. China, E-mail: lianghebust@163.com Wang Dianlong: E-mail: wdl@hebust.edu.cn, Diao Guangyun: E-mail: hndiaogy@163.com, Faculty of Material Science and Technology, Hebei University of Science and Technology, Shijiazhuang 050018, P.R. China higher mechanical properties, so it is widely used in production. Some researchers have studied the influence of different welding filler wires on the microstructure and properties of aluminum alloy welded joints. Liu [5] used the quenched-in microstructure and microsegregation of the mushy zone to explain why $\mathrm{Al}-\mathrm{Mg}$ alloys, despite their much wider freezing temperature range, can be less susceptible to solidification cracking than $\mathrm{Al}-\mathrm{Cu}$ alloys, and pointed out that the back diffusion of the magnesium element during the solidification process can reduce the generation of cracks. Chen [6] used ER4047, ER4043, ER2319 and a self-developed welding filler wires in the LY12 aluminum alloy welding. He pointed out that the combined action of Ti and $\mathrm{Zr}$ elements was beneficial to refine the weld microstructure and improve the performance of welded joints. Liu [7] compared the microstructure and properties of the double-pulsed MIG welds of the AA7075T651 joints filered by the ER7556 and ER5356 wires, and the results showed that the ER5556 filler wire was better. Compared with ER5556 welding wire, more second phases precipitated at grains boundaries at heat affected zone of the joint with ER5356 welding wire.

In this paper, the ER5356, ER5087 and ER4043 welding filler wires produced by SAF-FRO were selected for PMIG welding of $12 \mathrm{~mm}$ thick Al- $\mathrm{Zn}-\mathrm{Mg}$ aluminum alloy plate. After welding, the metallograph observation, the microhardness test and the tensile test were carried out. The effects of three kinds of welding wires on the microstructure and properties of welded joints were compared and analyzed.

\section{Materials and experimental procedures}

\section{Materials}

The base metal was commercial Al-Zn-Mg alloy of T4 temper in form of $12 \mathrm{~mm}$ thick plates. Two plates with dimension of $350 \mathrm{~mm}$ by $150 \mathrm{~mm}$ were used for butt welding. Square butt joint configuration, as shown in Figure 1, was prepared to fabricate the joints. The welding wires 


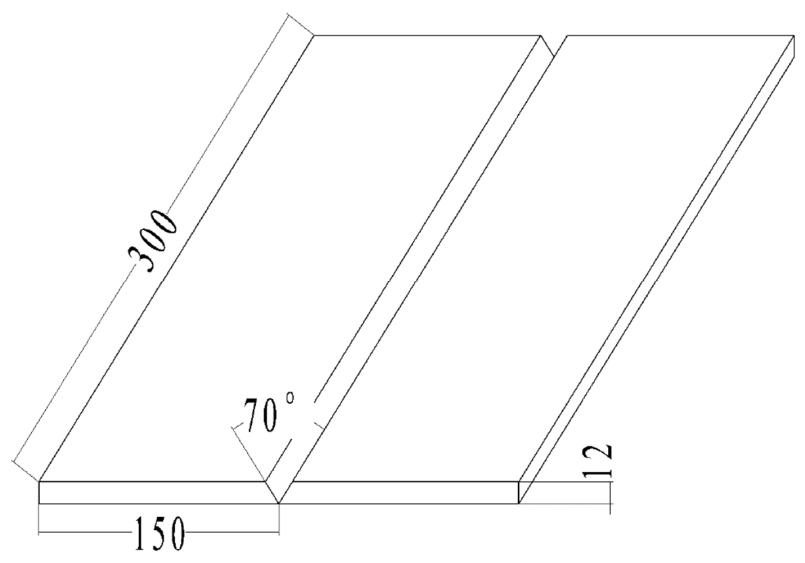

Figure 1: Square butt joints configuration (unit: $\mathrm{mm}$ ).

were three kinds of welding filler wires, which named ER5087, ER5356 and ER4043. The chemical compositions of the base materials and welding wires were given in Table 1.

\section{Experimental procedures}

The butt groove was in the form of V-groove with groove gap of $1 \mathrm{~mm}$ and unilateral bevel angle of $35^{\circ}$. The test plates were cleaned by mechanical methods before welding. A TPS 4000 power source made by Fronius was used. The shielding gas was pure Ar with purity not less than $99.99 \%$. Due to the excellent fluidity of Al-Si alloy, if the welding speed is slow, the liquid metal will flow forward and out of the arc area, resulting in non-fusion and other defects, so four layers six passes was used for ER4043 wire while three layers four passes were used for the other two wires. The specific welding process parameters are shown in Tables 2 and 3.

The microstructures and mechanical properties of welded joints were analyzed by cutting the metallographic samples, hardness samples and tensile specimens in the direction perpendicular to the weld. The microstructure of the specimens was investigated by the
Table 2: Welding process parameters by ER4043.

\begin{tabular}{llrrr}
\hline $\begin{array}{l}\text { Filler } \\
\text { wire }\end{array}$ & Welding passes & $\begin{array}{r}\text { Arc } \\
\text { voltage } \\
\text { (V) }\end{array}$ & $\begin{array}{r}\text { welding } \\
\text { current } \\
\text { (A) }\end{array}$ & $\begin{array}{r}\text { Welding } \\
\text { speed } \\
\left(\mathbf{c m} \cdot \mathbf{m i n}^{-1}\right)\end{array}$ \\
\hline ER4043 & 1st pass & 20 & 190 & 75 \\
& 2nd through 6th & 21 & 200 & 65 \\
& pass & & & \\
\hline
\end{tabular}

Table 3: Welding process parameters by ER5356\&ER5087.

\begin{tabular}{llrrr}
\hline Filler wire & Welding passes & $\begin{array}{r}\text { Arc } \\
\text { voltage } \\
\text { (V) }\end{array}$ & $\begin{array}{r}\text { welding } \\
\text { current } \\
\text { (A) }\end{array}$ & $\begin{array}{r}\text { Welding } \\
\text { speed } \\
\left(\mathbf{c m} \cdot \mathbf{m i n}^{-1}\right)\end{array}$ \\
\hline ER5356 & 1st pass & 23 & 215 & 65 \\
\&ER5087 & 2nd through & 24 & 225 & 45 \\
& 4th pass & & & \\
\hline
\end{tabular}

Zeiss optical microscope. The vickers microhardness was measured under a load of $500 \mathrm{~g}$ for $10 \mathrm{~s}$ on the cross section perpendicular to the welding direction along the middle line, and the interval between the adjacent points was $1 \mathrm{~mm}$. The tensile test was carried out using a Z100 E manufactured by Zwick. The fracture surfaces were observed using a TESCAN-VEGA3 scanning electron microscope.

\section{The welding heat input}

The welding heat input, which is determined by the welding parameters, has a significant impact on the microstructure and mechanical properties of the joint. In the experiment, the four layers six passes was used for ER4043 wire while three layers four passes were used for the other two wires. The welding heat input was calculated as follows:

$$
\begin{aligned}
& \mathrm{E}=\mathrm{UI} \eta / \mathrm{V} \\
& \mathrm{I} \text { - average welding current, A; }
\end{aligned}
$$

\begin{tabular}{|c|c|c|c|c|c|c|c|c|c|c|}
\hline Material & $\mathrm{Zn}$ & Mg & $\mathrm{Cu}$ & $\mathrm{Cr}$ & $M n$ & $\mathrm{Ti}$ & $\mathrm{Zr}$ & Si & $\mathrm{Fe}$ & Al \\
\hline Base metal & 4.60 & 1.20 & 0.20 & 0.20 & 0.15 & - & - & 0.35 & 0.40 & Bal \\
\hline ER5356 & 0.10 & $4.5-5.5$ & 0.10 & $0.05-0.20$ & $0.05-0.2$ & $0.06-0.2$ & - & 0.25 & 0.40 & Bal \\
\hline ER5087 & 0.25 & $4.5-5.2$ & 0.05 & $0.05-0.25$ & $0.7-1.1$ & $<0.15$ & $0.1-0.2$ & 0.25 & 0.40 & Bal \\
\hline ER4043 & $<0.1$ & $<0.20$ & $<0.3$ & - & $<0.05$ & $<0.15$ & - & $4.5-6.0$ & $<0.6$ & Bal \\
\hline
\end{tabular}

Table 1: Chemical composition of base metal and welding wire (wt \%). 
$\mathrm{U}$ - average arc voltage, $\mathrm{V}$;

$\mathrm{V}$ - welding speed, $\mathrm{cm} / \mathrm{s}$;

$\eta$ - coefficient of thermal efficiency, for P-MIG $\eta$ is 0.7 .

Under the same welding parameters, ER5356 and ER5087 wire had the same welding heat input, as follow:

$\mathrm{E}=\mathrm{U}_{1} \mathrm{I}_{1} \eta / \mathrm{V}_{1}+\mathrm{U}_{2} \mathrm{I}_{2} \eta / \mathrm{V}_{2}+\mathrm{U}_{3} \mathrm{I}_{3} \eta / \mathrm{V}_{3}+\mathrm{U}_{4} \mathrm{I}_{4} \eta / \mathrm{V}_{4}$

$=18.3 \mathrm{KJ} . \mathrm{cm}^{-1}$

The welding heat input of ER4043 wire was as follow: $\mathrm{E}=\mathrm{U}_{1} \mathrm{I}_{1} \eta / \mathrm{V}_{1}+\ldots .+\mathrm{U}_{6} \mathrm{I}_{6} \eta / \mathrm{V}_{6}$ $=15.7 \mathrm{KJ} . \mathrm{cm}^{-1}$

\section{Results and discussion}

\section{Microstructure of the welds}

The macroscopic metallographic specimens were cut from the weld, and the macrostructures obtained after grinding and etching were as shown in Figure 2. ER5356 and ER5087 welding wires had large amount of metal in the single weld, and the remelting effect of the previous weld pass on the first pass was obvious.

The microstructure of the weld filled by ER5356 was shown in Figure 3. The metallograph of the root pass was shown in Figure 3(a). It can be seen that the columnar crystals grew in the direction perpendicular to the fusion boundary, and the equiaxed crystal zone was formed in the weld center. Figure 3(b) and (c) showed the microstructure of the filling and cover pass of the weld, respectively, almost all of which was the equiaxed crystal structure of smaller grain size. The decrease of the columnar crystal structure and the increase of the equiaxed crystal structure were due to the decrease of the temperature difference in the weld pool of the cover pass, and the decrease of the temperature gradient at the front of the solidification interface in the molten pool. The decrease of the temperature gradient leaded to greater degree of undercooling. The refinement of crystal structure was determined by the high nucleation rate under large undercooling.

The microstructure of the weld filled by ER5087 was shown in Figure 4. The metallograph of the root pass was shown in Figure 4(a), less columnar crystals in the center of the root pass were observed and equiaxed crystals formed. The microstructure of the filling pass was shown in Figure 4(b), the filling pass consist mainly of columnar dendrites and a small amount of equiaxial crystals. The microstructure of the cover pass was shown in Figure 4(c), the microstructure in cover pass zone consist of fine equiaxed grains. Compared with the weld filled by ER5356, the columnar crystals increased and the grain coarsened in the microstructure of the weld filled by ER5087.

The microstructure of the weld filled by ER4043 was shown in Figure 5. It can be seen that the weld had a typical
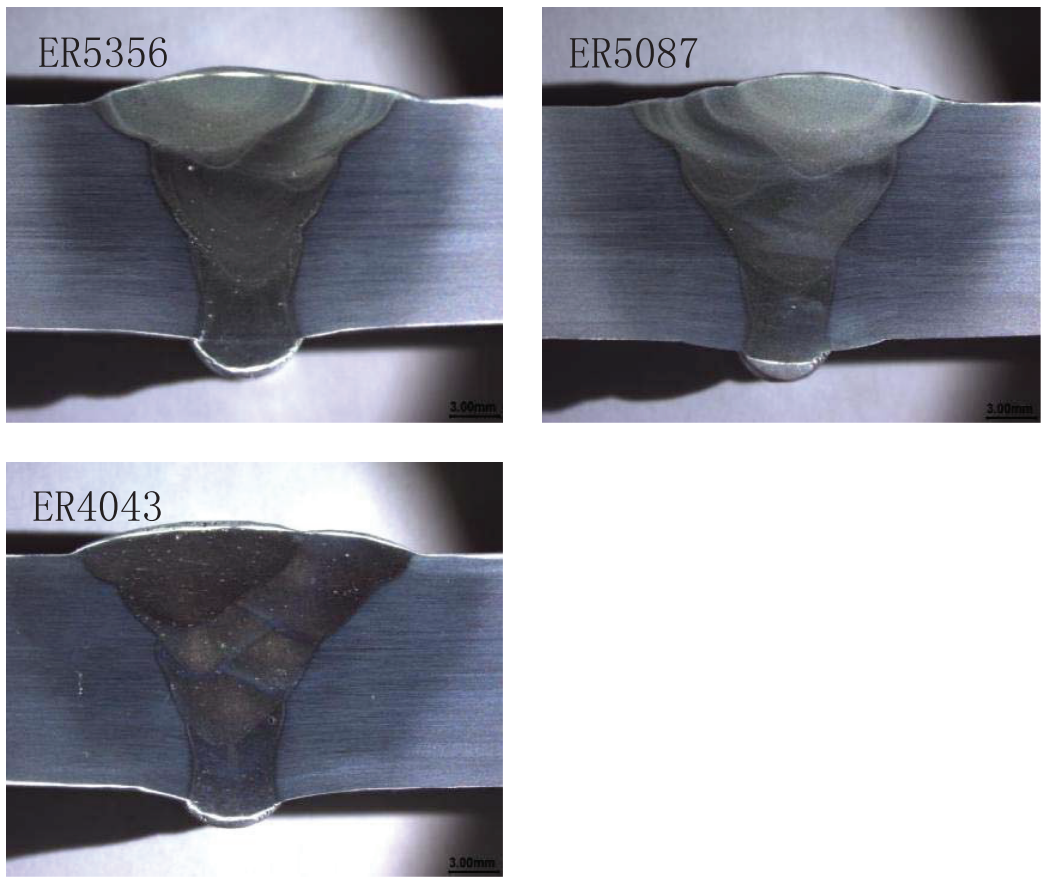

Figure 2: Macro morphologies of weld cross section. 


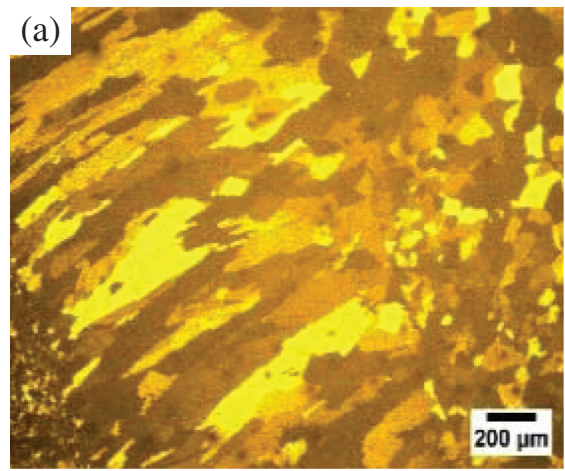

root pass

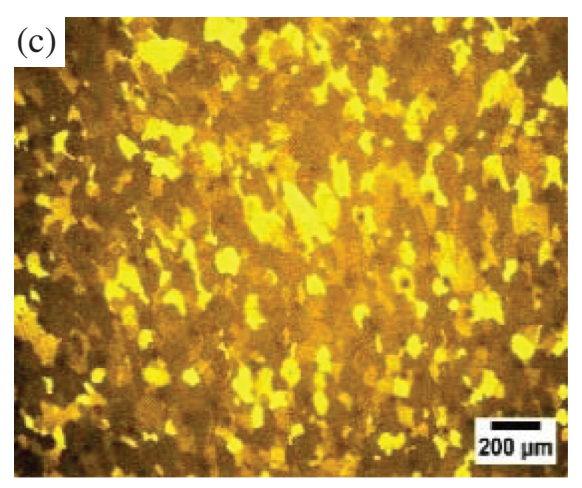

cover pass

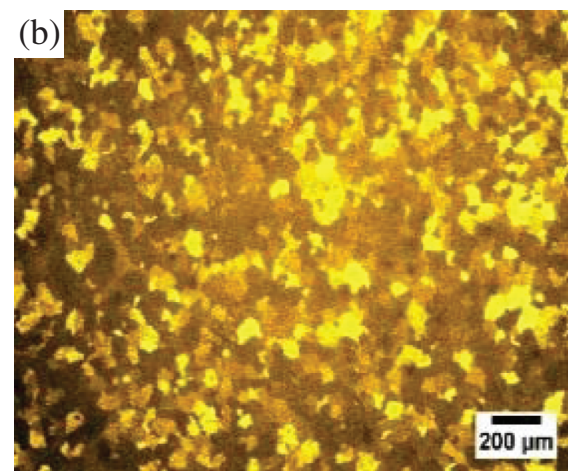

filling pass

Figure 3: Microstructure of weld by ER5356.

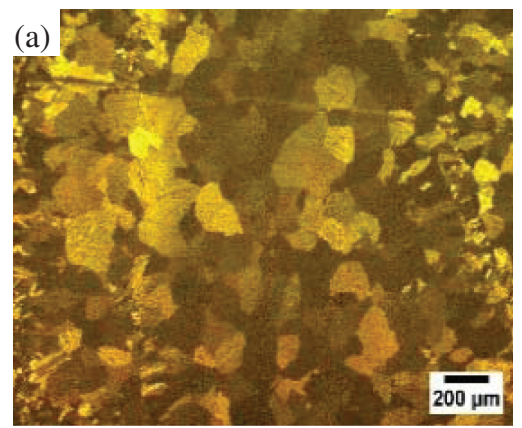

root pass

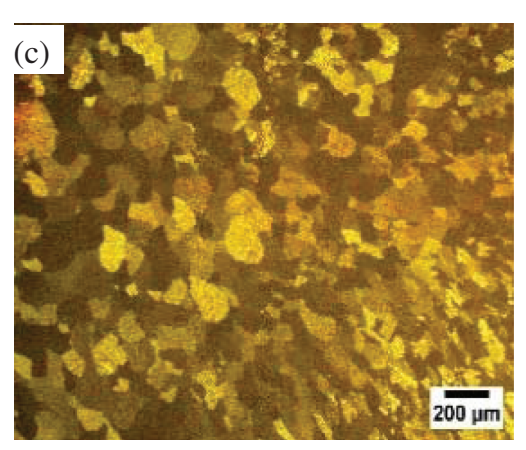

cover pass

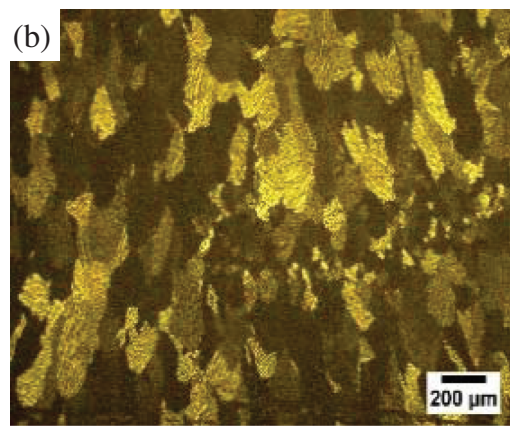

filling pass 


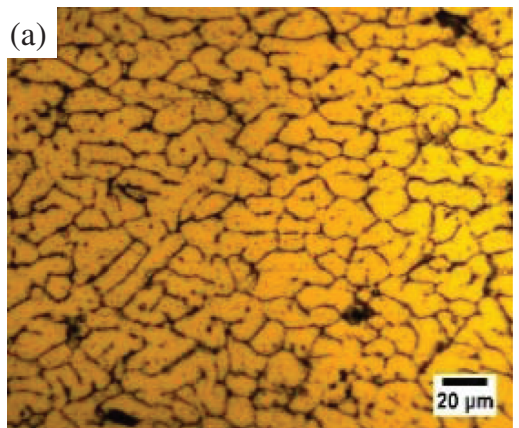

root pass

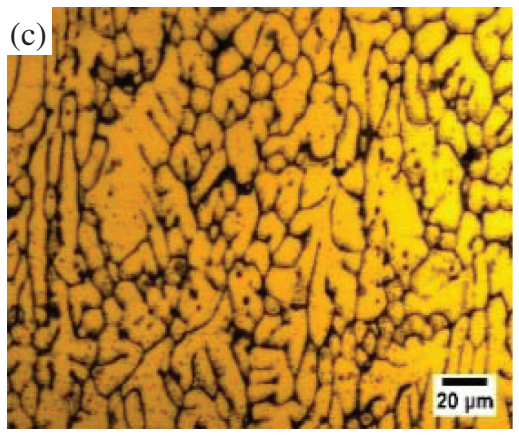

filling pass

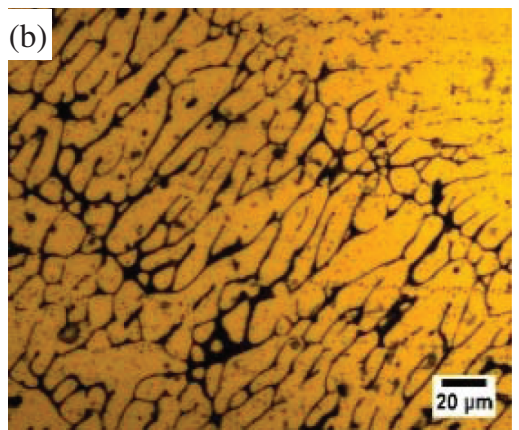

the fusion zone

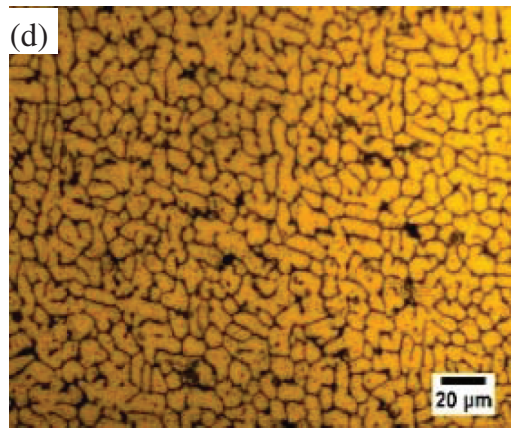

cover pass

Figure 5: Microstructure of weld by ER4043.

eutectic structure. Figure 5(a) and (d) were the microstructures of the root and cover pass respectively. The weld zone consists of equiaxed grains with uniform grain size. The microstructure of the fusion zone of filling pass was shown in Figure 5(b). This zone was made up of dendrites and a small amount of equiaxed grains. The microstructure of the filled pass was shown in Figure 5(c), It was composed of mainly columnar dendrites and a small amount of equiaxed grains.

From the Figure 6, The reheating of the heat affected zone near the fusion zone in the weld of the two types of five series welding wire was affected by the heat input, while the matrix grains were coarsened. The parent metal was far away from the weld, and the zone was less affected by the thermal cycle, so it was still exhibited the original rolling state. However, The heat affected zone of ER4043 weld had a smaller peak temperature of the weld thermal cycle, and the microstructure changes were not obvious, the original rolling state was basically maintained.

\section{Microhardness test}

Comparison of the microhardness profile of the three joints was shown in Figure 7. The test results of the joints filled with ER5356, ER5087 and ER4043 showed that the locations of the lowest hardness were all in the center of cross section, and the minimum values were $71 \mathrm{HV}, 76 \mathrm{HV}$ and $63 \mathrm{HV}$, respectively. There were softening phenomenon in the heat-affected zones of the three welded joints, where the strengthening effect was lost due to coalescence and growth of the strengthen phases during the welding thermal cycling. The ER4043 wire filled joints had the least degree of softening of the heat affected zone. The ER4043 wire was at a high temperature for shorter time than the ER5356 wire and ER5087 wire. It was found that the weld filled by ER5087 had the highest hardness and the filled by ER4043 had the lowest hardness. The ER5087 and ER5356 wires had higher alloy elements than ER4043, and the alloy elements Fe, Ti, Mn and Cr form the second phase element with lower solid solubility, which increased the amount of internal precipitation strengthening phase and improved the hardness [8]. 


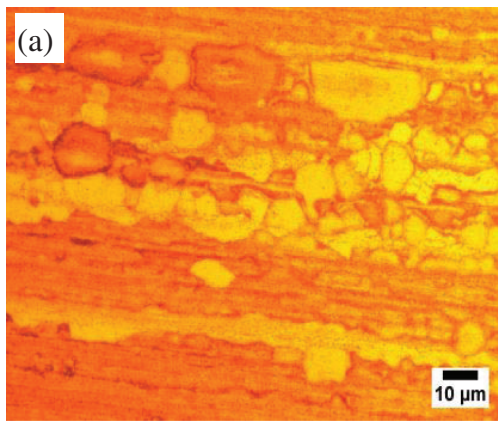

ER5356 wire

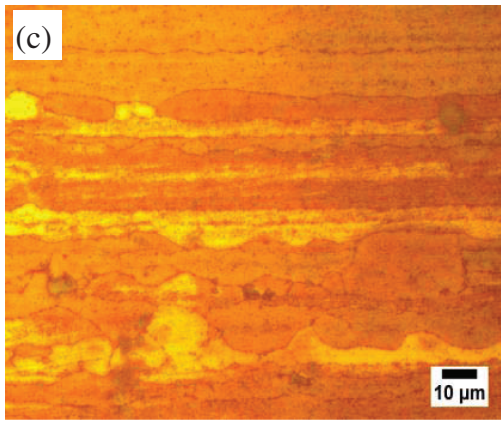

ER4043 wire

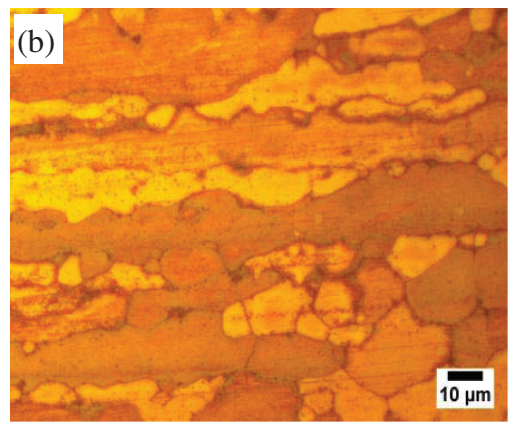

ER5087 wire

Figure 6: Microstructure of the heat affected zone.

\section{Tensile properties}

Figure 8 shows the pictures of the specimens after the tensile test. The locations of the fracture were all located in the weld zone. Figure 9 shows the macroscopic topography of the fracture. The fracture was dark gray with a certain degree of concavity and convexity. Figure 10

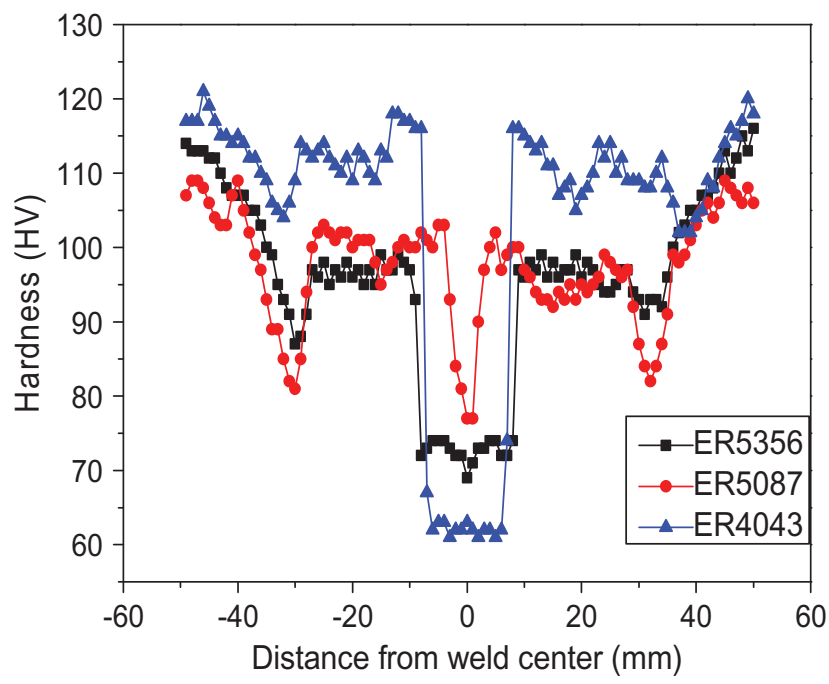

Figure 7: Microhardness distribution. shows the comparison of the tensile curves of three welding wire welds. It can be seen that the tensile strength of the ER5087 welding wire was superior to the other two welding wires. The results of the tensile test were shown in Table 4. When ER5087 was used as the filling material, the welded joint had the highest ultimate strength, and the value reached $313 \mathrm{MPa}$ on average. When the ER5356 was used as the filling material, the welded joint had the

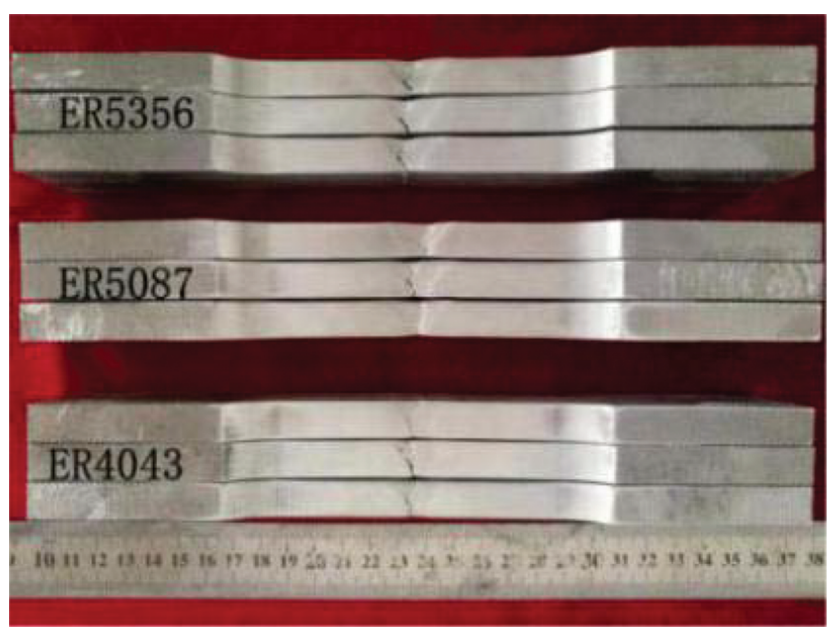

Figure 8: Fracture images of joints. 


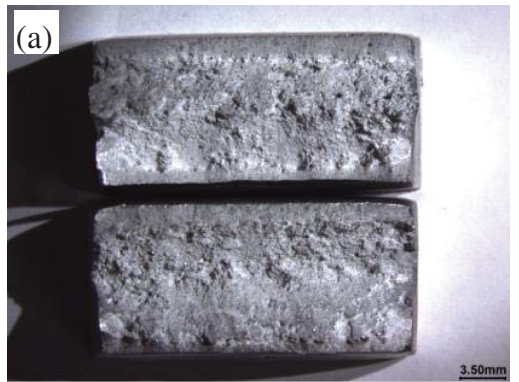

ER5356 wire

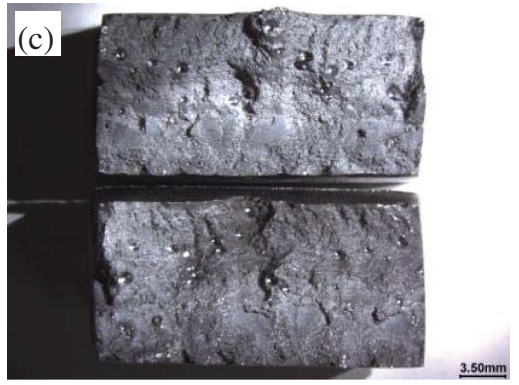

ER4043 Wire

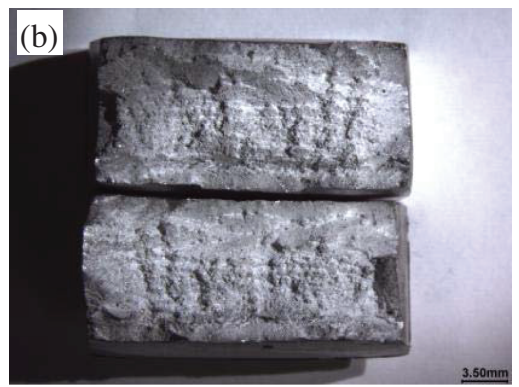

ER5087 wire

Figure 9: The macroscopic topography of the fracture.

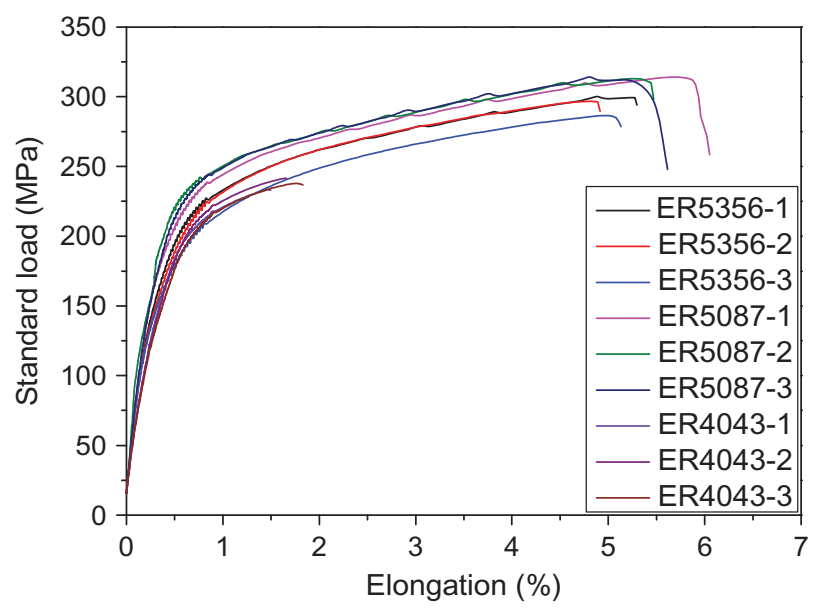

Figure 10: The tensile curves.

largest elongation, and the value reached 7.9\%. Because the content of $\mathrm{Fe}, \mathrm{Ti}, \mathrm{Mn}$ and $\mathrm{Cr}$ elements in ER5087 was the highest in the three kinds of welding wires, the amount of precipitation strengthening phase was increased, and as a result the joint's strength was increased. The elongation of the joint with ER5087 wire was reduced compared with ER5356 because of its larger grain size in the fusion zone. The joint filled by ER4043 had the lowest strength and elongation due to the low plasticity of the Al-Si eutectic structure.

\section{Fractography}

In order to discuss the tensile fracture mechanism of the welded joints, the tensile fracture of the specimens were scanned by scanning electron microscopy(SEM), as shown in Figure 11. As can be seen from Figure 11(a) and (b), the fracture mode of welding joints of $\mathrm{Al}-\mathrm{Mg}$ filling wires were ductile fracture under tensile stress, and the fracture was filled with dimples and second phases When the ER5087 was used as the filling material, the number of the second phase particles was increased, and the shape of the dimples was elongated. The fracture of the joint with ER4043 wire was intergranular dimples fracture under tensile stress, and fracture surface of the grain boundary had a large number of small dimples, as shown in Figure11(c). The fracture location was near to the fusion line. The metallographic analysis showed that there was a large amount of columnar crystals at the fusion line. On the columnar crystals plane of aluminum alloy, the bond between the second phase particles and the grain was weak. Under the condition of stress concentration and so on, the second phase particles and the 
Table 4: Tensile strength of welded joints filled with different welding wires.

\begin{tabular}{|c|c|c|c|c|}
\hline Filler wire & Tensile strength(MPa) & Yield strength(MPa) & Percentage reduction of area( $\mathrm{Z} \%)$ & Percentage elongation after fracture(A\%) \\
\hline ER5356 & 294 & 175 & 15.1 & 7.9 \\
\hline ER5087 & 313 & 202 & 14.2 & 7.6 \\
\hline ER4043 & 237 & 179 & 5.7 & 1.6 \\
\hline
\end{tabular}

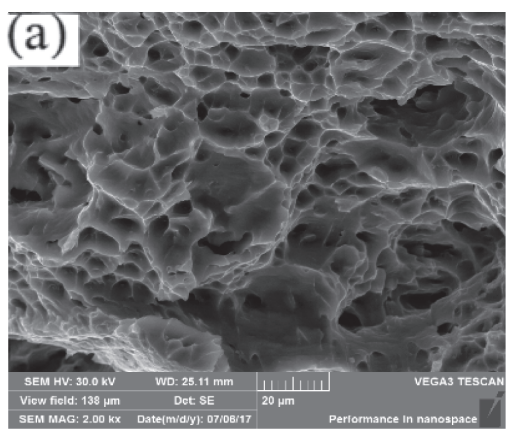

fracture surface of weld seam by ER5356

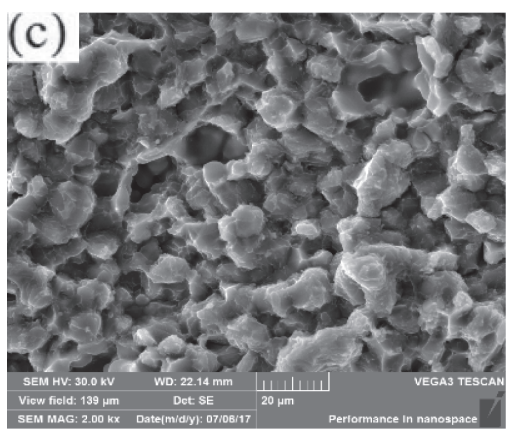

fracture surface of weld seam by ER4043

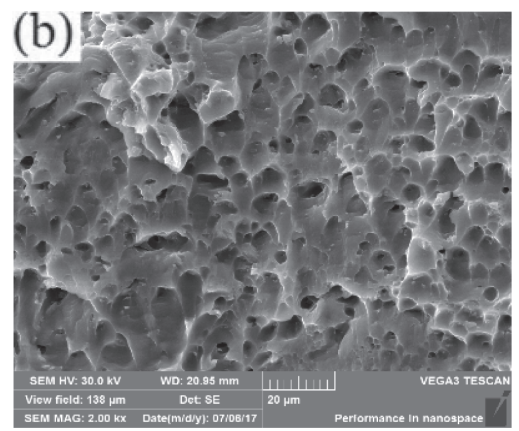

fracture surface of weld seam by ER5087

Figure 11: SEM images of the weld joints fracture surface.

plastic deformation of the matrix was not coordinated and produce micropore, The voids of nucleation, growth, continuous accumulation and continue to produce new microporous, eventually lead to fracture [9].

\section{Conclusions}

(1) The weld filled with ER5356 wire has larger zone of the finer equiaxed grains, while the weld filled with ER5087 has more columnar crystals near the fusion line and the larger equiaxed grains in the center. The weld filled with ER4043 has the typical eutectic structures.
(2) The lowest hardness appeared at the center line for all the three joints. The weld filled with ER5087 has the highest hardness value, while the weld filled with ER4043 has the lowest hardness value.

(3) The ultimate strength of the joint with ER5087 wire is the highest, and the joint with ER4043 has the lowest strength. The strength of welded joint filled with ER5356 is slightly lower than that of ER5087, but the percentage elongation after fracture is the highest.

(4) The ER4043 welding wire with the lowest welding heat input has the lowest degree of softening. The heat affected zones of ER5356 and ER5087 weld have a higher peak temperature of the weld thermal cycle, and have severe softening of heat affected zones. 


\section{References}

[1] W.S. Miller, L. Zhuang, J. Bottema, A. Wittebrood, P. De Smet and A. Haszler, Mater. Sci. Eng. A, 280 (2000) 37-49.

[2] S.D. Ji, X.C. Meng, Z.W. Li, L. Ma and S.S. Gao, Int. J. Adv. Manuf. Technol., 84 (2016) 2391-2399.

[3] A. Heinz, A. Haszler, C. Keidel, S. Moldenhauer, R. Benedictus and W.S. Miller, Mater. Sci. Eng. A, 280 (2000) 102-107.
[4] E.A. Starke Jr and J.T. Staley, Pro. Aero. Sci., 32 (1996) 131-172.

[5] J. Liu, H.P. Duarte and S. Kou, Acta. Mater., 122 (2017) 47-59.

[6] H. Chen, C.G. Yang, Q. Zheng, Y. He and I.W. Yu, Hot Work. Technol., 43 (2014) 159-161.

[7] C.J. Liu, J. Sun, W. Zhang, S. He and Y. Su, Hot Work. Technol., 45 (2015) 203-205.

[8] Z.S. Wu, P.F. Jin and S. Gao, Weld. Technol., 39 (2010) 1-11.

[9] W. Zhang and R.S. Xiao, Chin. J. Laser., 9 (2014) 1-7. 